\title{
Particle Characterization of Environmental Soots via HRTEM and XPS Techniques
}

\author{
R. L. Vander Wal*, V. M. Bryg** \\ *Penn State University, Dept. of Energy and Mineral Engineering, The EMS Energy Institute and \\ The Penn State Institutes of Energy and the Environment, University Park PA 16802 \\ ** The Universities Space Research Association (USRA) at NASA-Glenn Research Center, 21000 \\ Brookpark Rd. Cleveland, $\mathrm{OH} 44135$
}

In the last decade research has focused on quantification of the impact of aircraft emissions on the ozone layer, greenhouse gases and the climate impact of aerosols. Yet there have been relatively few studies of aircraft and ground support equipment on airport and regional air quality. The U.S. Environmental Protection Agency (EPA) estimates that airport emissions now make up about 2 percent of the total non-road emissions.

On-road vehicle emissions are strictly regulated along with (soon) those from off-road vehicles such as diesel locomotives and earth moving equipment. Emissions associated with airports presently remains unregulated and without impending regulatory limits, despite the broad public exposure compared to off-road vehicles. Jet engines of aircraft are the dominating emission source at major airports. Most travelers have upon occasion smelled jet exhaust. Within this exhaust are innumerable nanoparticles, generally invisible to the eye except when in large concentrations. Presently such exposures are frequent or continual for ground support crews and for flight personnel.

Transmission electron microscopy (TEM) of jet exhaust particulate matter can provide direct measures of particle size and their change with respect to engine power. Of particular concern are the innumerable small particles produced at idle conditions as illustrated in Fig. 1. Such particles of $<20 \mathrm{~nm}$ size can easily reach the deepest recesses of the lung, the alveoli. Such particles may arise by volatile condensation. Their amorphous structure is consistent with XPS characterization that indicates a high organic content.

As the power changes, so too does the particle crystallinity, as illustrated by the HRTEM images in Fig. 2. The non-crystalline and crystalline nanoparticles were collected at idle and near full power from a CFM-56-2C1 engine running on standard JP-8 fuel collected during the NASA-led Alternative Aviation Fuels Experiment (AAFEX) field campaign (2009) using NASA's DC-8 aircraft. Just as for inorganic nanomaterials such as $\mathrm{SiO}_{2}$ or $\mathrm{TiO}_{2}$, particle crystallinity has a profound effect upon the toxicity of the material (quartz vis-à-vis amorphous silica).

Complementing TEM for particle physical size and nanostructure characterization is X-ray Photoelectron Spectroscopy (XPS) for measuring particle surface chemistry. Partially oxidized carbon, such as soot within combustion exhaust supports various oxygen functional groups such as phenolic $(-\mathrm{OH})$, carbonyl $(-\mathrm{C}=\mathrm{O})$ and carboxylic $(-\mathrm{COOH})$. The relative concentration of these groups determines the particle acidic nature and the potential chemical interaction(s) with the epithelial cell membranes of the airways and lung tissue. Again, by way of reference, the chemical phenol, with structure essentially identical to a localized surface section of soot is a known lung irritant. 
XPS has also revealed a surprising content of heteroelements in aircraft engine soots. Elements such as $\mathrm{Ti}, \mathrm{Ba}, \mathrm{Co}, \mathrm{Fe}$ etc. are present at levels of tenths of atomic percent and higher. Their presence and concentration is highly dependent upon both engine and power level. Significant concentrations of transition metals at the surface of such soots create an entirely new dimension of concern. Elements such as Co are toxic and Fe participates in the well-known Fenton reaction that ultimately produces reactive oxygen species (ROS).

Other soots (from strictly ground-based sources) will be compared to those particulate exhaust emissions collected from jet aircraft (as referenced above) using these electron-based characterization tools.

\section{Acknowledgements}

[1] Funding for this work was through the NASA Fixed Wing (SWF) NRA, NASA cooperative agreement NNX09AD42A, with Penn State University and with USRA/NCSER.

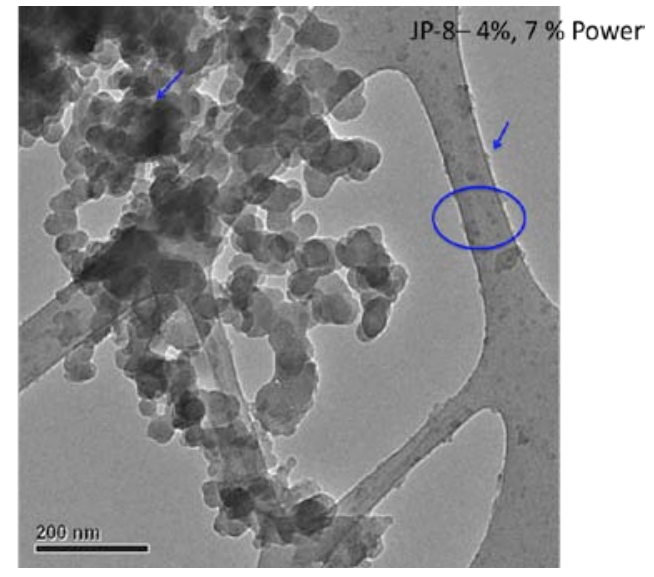

Figure 1. (left) A low magnification TEM image showing the myriad nanoparticles collected from the exhaust of a jet engine operating at low (idle) conditions.

Figure 2. (below) High resolution TEM images of particulate matter sampled from the exhaust of a CFM56 jet engine aboard a NASA DC-9 aircraft. Illustrated is the difference between amorphous structure at low power and crystalline content at high engine power.

\section{Comparative Nanostructure}

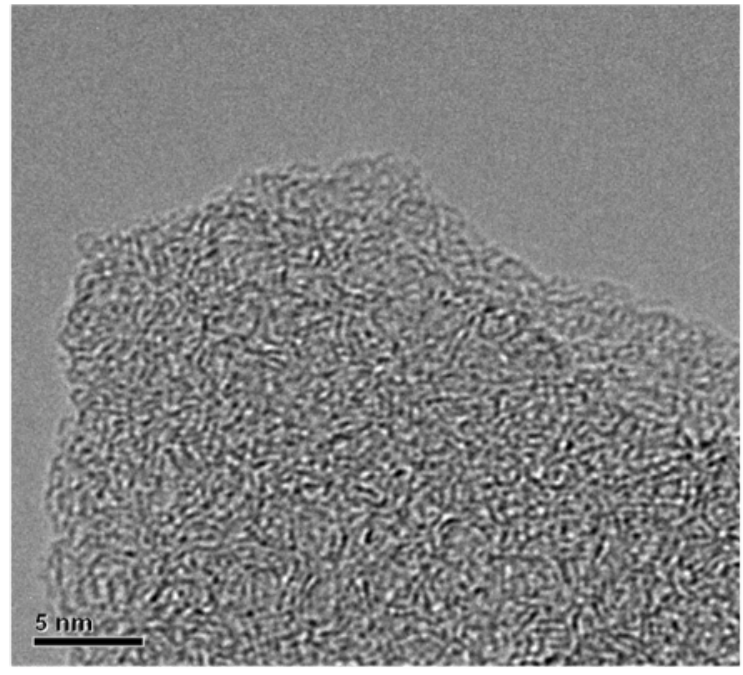

4\%, 7\% Power

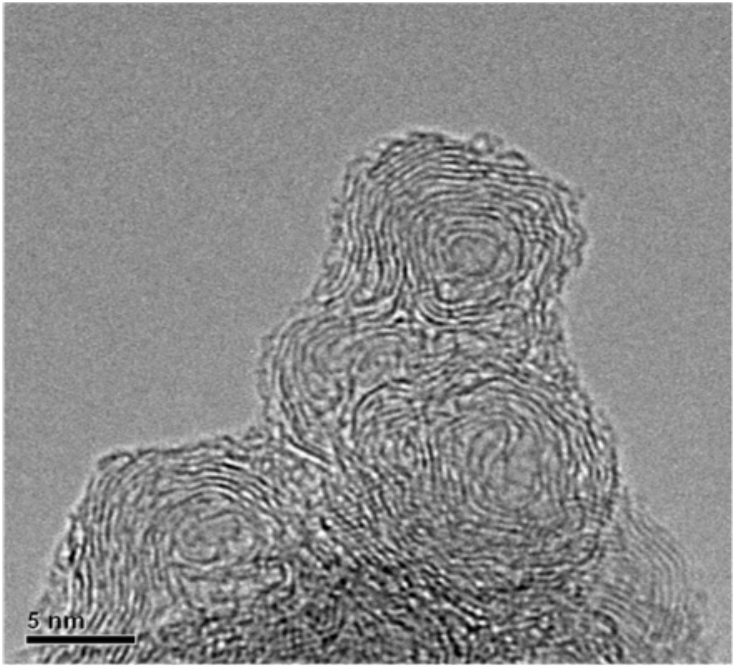

$100 \%$ Power 